\title{
Rejoinder
}

Joseph A. Aistrup, Fort Hays State University

The commentary of our colleagues is appreciated. Even though this reply will not settle this controversy, it might provide a starting point for others wishing to examine this topic.

The article had two major findings. The first is that there was a minimal Democratic bias in contested southern state legislative districts in the 1970s and 1980s. The second is that the Democrats appear to have used the switch from multimember districts (MMDs) to single-member districts (SMDs) to insulate themselves from large vote swings by lowering the swing ratio (responsiveness) of the electoral system. Krassa and Combs make two criticisms of this research: First, the grouping time periods together means the analysis includes the effects of other structural and social events, thus confounding the analysis of changes in the swing ratio and bias. They suggest a need to adopt a similar methodology to King and Gelman (1991), which controls for the structural characteristics in southern state legislative elections. Their second critique is the interpretation of a declining swing ratio protecting incumbents is incorrect. A more desirable situation for Democratic incumbents is to have a high swing ratio because it converts lower vote shares into a higher proportion of Democratically controlled districts. Bullock's critique notes the findings are not generalizable to the affirmative action gerrymandering associated with the 1990s redistricting process. I begin by addressing the methodological critique of Krassa and Combs. Then I turn to the latter two questions involving the interpretation of our findings.

\section{A New Method of Analysis}

In the May 1994 volume of the American Journal of Political Science, Gelman and King published "A Unified Method of Evaluating Electoral Systems and Redistricting Plans" (514-549) and made available a statistical software package to analyze two-party electoral systems. In reply to the

JOSEPH A. AISTRup is Assistant Professor of Political Science and Assistant Director of the Docking Institute of Public Affairs at Fort Hays State University in Hays, Kansas.

The American Review of Politics, Vol. 16, Spring, 1995: 49-58

${ }^{\circledR} 1995$ The American Review of Politics 
methodological critique of Krassa and Combs, the southern state senate elections are reanalyzed using methodology developed by Gelman and King $(1994,517-26)$. It is important to note that the high rate of uncontested elections and the presence of free-for-all MMDs test the limits of this methodology. Because of this, I chose only to analyze state senate elections for this rejoinder. Put simply, there are fewer MMDs to control for in the analysis. After a brief discussion of Gelman and King's (1994) analytical techniques, I outline how I attempt to control for these problems.

Gelman and King's (1994) estimation technique is a two step process. The first step is to estimate two error terms, SIGMA and LAMBDA, using information from the election cycles prior to and after the election cycle under study. For each election cycle in a decade, estimates for SIGMA and LAMBDA are then pooled. This enables us to generate a hypothetical model to derive estimates of the bias and responsiveness of the electoral system. The advantage of this methodology is that it does not make the uniform partisan swing assumption and it provides an estimation of uncertainty including the standard errors for the estimates of the bias and responsiveness. In addition, their model allows for additional specifications for incumbency, contestedness, prior voting patterns, and district format. ${ }^{1}$

Unfortunately, this methodology is not a panacea when analyzing the southern state legislative electoral system. Controlling for free-for-all MMDs and MMDs with-positions still represents major concerns. Gelman and King (1994) note that their methodology is not sound when there are numerous MMDs. In the 1970s, Florida and South Carolina had MMDs with-positions (Florida has staggered elections.) and North Carolina had free-for-all MMDs. After the 1980s redistricting, North Carolina was the only state to keep its MMD format.

For this analysis, MMDs with-positions are of less concern than freefor-all MMDs. In MMDs with-positions voters choose between a defined set of candidates, thus enabling a valid and reliable calculation of the Democratic proportion of two-party vote. This is not the case with free-for-all MMDs where the top vote-getters win. For these districts, the proportion of Democratic two-party vote is derived using Niemi et al.'s (1991) methodology of pairing candidates according to party, and based on the top versus lowest vote-getter. The problem with this methodology is that it may not accurately reflect the distribution for voters' choices in a free-for-all format. Despite this potential problem, North Carolina remains included in the analysis so that the original findings can be compared with those presented in this reply. When estimating the bias and responsiveness of the state senate districts in the South, MMDs with-positions and free-for-all MMDs are controlled with separate dummy variables. 
The demands of the estimation model led to the exclusion of Mississippi from the analysis because it redistricted before every election in the 1970 s, thus precluding the ability to use the post- and pre-election information. Arkansas and Alabama are also excluded from this analysis. During the 1970 s, fewer than $20 \%$ of all state senate elections were contested. When the percentage of contested elections is so minimal, speculation about the effects of redistricting become more a matter of historical examination and conjecture rather than empirical analysis. As Gelman and King (1994, 536) note, when the expected vote for a party is $20 \%$ or less, there is no model that can accurately predict the bias and responsiveness of the electoral system if the percentage of vote should theoretically rise to $50 \%$. Finally, data for state legislative races only extend back to 1968 . Because of the demands of the model, an estimate of the bias and responsiveness of the election cycle before the 1970 s redistricting is not possible.

Taken together, this means state senate elections from Florida, Georgia, North Carolina, South Carolina, Tennessee, Texas, and Virginia are analyzed. Given that only contested elections were analyzed my previous article and the minimal number of contested elections from the three states now excluded (a total of 32 contested districts for all three states in the election cycle prior to the 1980 s redistricting), this analysis and the previous analysis are comparable.

Unfortunately, even excluding the three states, uncontested elections still represent a major concern in this analysis. There are a number of ways to handle uncontested districts. One choice is to code these districts as 1 for an uncontested Democratic seat (indicating that the percentage of Democratic two-party vote is $100 \%$ ) and 0 for an uncontested Republican seat. This has the effect of decreasing the bias for the party that wins more uncontested seats (Gelman and King 1994, 549). To remedy this situation it is necessary to impute election results. ${ }^{2}$ King and Gelman provide an imputing procedure that incorporates uncertainty to estimate proportion of Democratic two-party vote. ${ }^{3}$

It is important to realize that with so many uncontested elections (about $50 \%$ ) by the GOP, and, more importantly, that many were virtually uncontested for decades (up to the late 1970s), imputing the proportion of Democratic support artificially generates roughly half of the election results. Even though King and Gelman suggest setting the initial value for imputation of .25 for uncontested Republican contests and .75 for uncontested Democratic contests, the sad state of local southern GOP state parties in the 1970s and early 1980 s suggests that these values need to be shifted to reflect a lower level of Republican party support. 
Because most uncontested seats were held by Democratic incumbents in the South, it is important to examine the proportion of Democratic vote when incumbents are contested in seats that have experienced a limited amount of party competition. An examination of this situation shows that this type of Republican candidate will typically garner anywhere from five to $25 \%$ of the vote. Thus, the initial values for imputing uncontested results are set at .35 for Republican uncontested seats (reflecting the generally greater base of support for Democrats in the South) and .85 for Democratic uncontested seats (about 15\% Republican votes).

The last major methodological concern is to assess the how the bias and responsiveness of MMDs with-positions varies in comparison to SMDs. To analyze this condition, the counterfactual situation of no MMDs withpositions is specified. Significantly, in this analysis, I continue to control for free-for-all MMDs because of the theoretical differences when comparing free-for-all districts versus those with paired candidates.

Thus, the following procedures are used for this analysis:

1) Estimate SIGMA and LAMBDA respectively for three election cycles in the pre-1980s redistricting period and two in the post-1980s redistricting period. Table 1 shows the election year cycles as it applies to each state in the analysis. To estimate SIGMA, incumbency of the district (coded 1 for Democratic, 0 if open, and -1 for Republican control), prior contestation (coded 1 if contested, and 0 if not contested), partisan election year advantage (coded 1 if off-year election with a Republican president or presidential election year when a Democrat wins the presidency (1976), and 0 for the other election years), and prior proportion of Democratic vote (if available) were used. LAMBDA is estimated using the proportion of Democratic vote in the next election.

Table 1. Election Cycles Analyzed for Each State

\begin{tabular}{llllll}
\hline & \multicolumn{2}{c}{ Pre-1980s Redistricting } & \multicolumn{2}{c}{ Post-1980s } \\
Cycles & 1st & 2nd & 3rd & 1st & 2nd \\
\hline Florida & 72 & $74-6$ & $78-80$ & 82 & $84-6$ \\
Georgia & 76 & 78 & 80 & 82 & 84 \\
North Car. & 76 & 78 & 80 & 84 & 86 \\
South Car. & 72 & 76 & 80 & 84 & 88 \\
Tennessee & $72-4$ & $76-8$ & $80-2$ & $84-6$ & $88-90$ \\
Texas & 72 & $74-6$ & $78-80$ & 82 & $84-6$ \\
Virginia & 71 & 75 & 79 & 83 & 87 \\
\hline
\end{tabular}


2) Use the summary statistics for SIGMA and LAMBDA to derive estimates for the bias and responsiveness of the southern state senate electoral system for the election cycle prior to the 1980s redistricting, the first election cycle after the 1980s redistricting, and the second election cycle after the 1980s redistricting. These estimates are derived by controlling for incumbency, prior level of incumbency, current contestation, prior level of contestation, partisan election year advantage, prior proportion of Democratic vote, and dummy variables representing MMD with-positions and free-for-all MMDs, respectively.

3) Repeat step 2) except for specifying the counterfactual situation of no MMDs with-positions.

Based on my earlier article I should find that the bias of the pre-1980s and post-1980s periods are very close to 0 . I also should find that the responsiveness of the system between the redistricting periods declines. When specifying the counterfactual situation of no MMDs with-positions, the bias of the party system is expected to move toward a more favorable Democratic orientation (The previous analysis MMDs showed a slight bias toward the GOP.) and the estimate of the responsiveness is expected to decline after redistricting (MMDs were found to have a high swing ratio.). Table 2 and Figures 1, 2, and 3 show only partial support for our previous efforts.

Table 2. Findings for the Analysis of the Bias and Responsiveness for Southern State Senate Elections

\begin{tabular}{|c|c|c|c|c|c|c|}
\hline & \multirow[b]{2}{*}{ SIGMA } & \multirow[b]{2}{*}{ LAMBDA } & \multicolumn{2}{|c|}{ Full Model } & \multicolumn{2}{|c|}{ Counterfact Model } \\
\hline & & & Bias & Respon. & Bias & Respon. \\
\hline Pre-1980s & .0893 & .4149 & $\begin{array}{l}.021 \\
(.01)\end{array}$ & $\begin{array}{l}3.461 \\
(.15)\end{array}$ & $\begin{array}{l}.016 \\
(.01)\end{array}$ & $\begin{array}{l}3.437 \\
(.12)\end{array}$ \\
\hline $\begin{array}{c}1 \text { st cycle } \\
1980 \text { s }\end{array}$ & .0995 & .4608 & $\begin{array}{c}.015 \\
(.004)\end{array}$ & $\begin{array}{l}3.191 \\
(.09)\end{array}$ & \multicolumn{2}{|c|}{$\begin{array}{c}\text { No MMDs } \\
\text { with-positions }\end{array}$} \\
\hline $\begin{array}{l}\text { 2nd cycle } \\
1980 \mathrm{~s}\end{array}$ & .0967 & .4608 & $\begin{array}{c}.022 \\
(.005)\end{array}$ & $\begin{array}{l}3.114 \\
(.09)\end{array}$ & \multicolumn{2}{|c|}{$\begin{array}{c}\text { No MMDs } \\
\text { with-positions }\end{array}$} \\
\hline Standard e & are in $p$ & arentheses. & & & & \\
\hline
\end{tabular}


Figure 1. Seats-Votes Curve for 1970s Election Cycle Before Redistricting

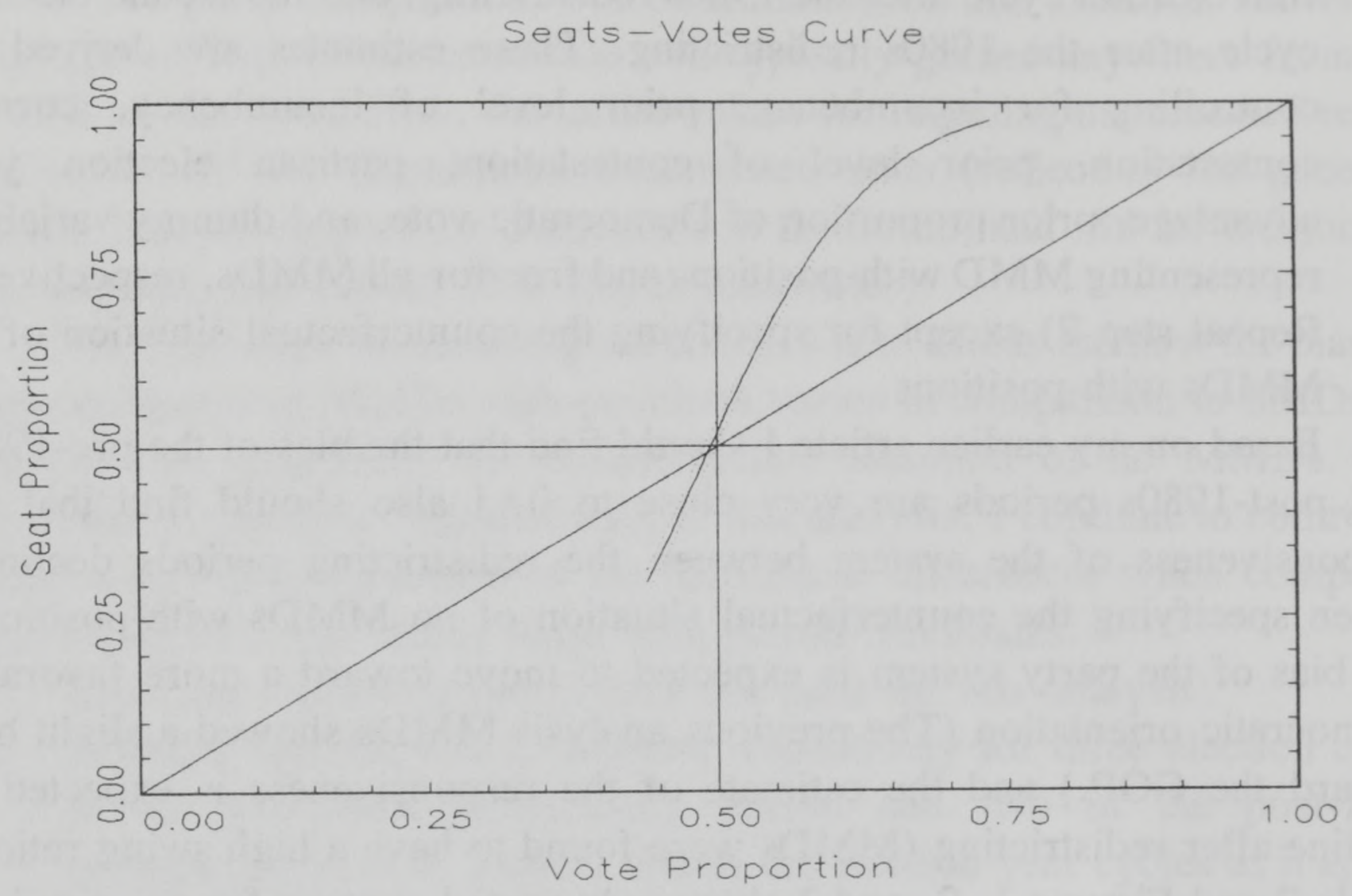

Figure 2. Seats-Votes Curve for 1980s, First Election Cycle After Redistricting

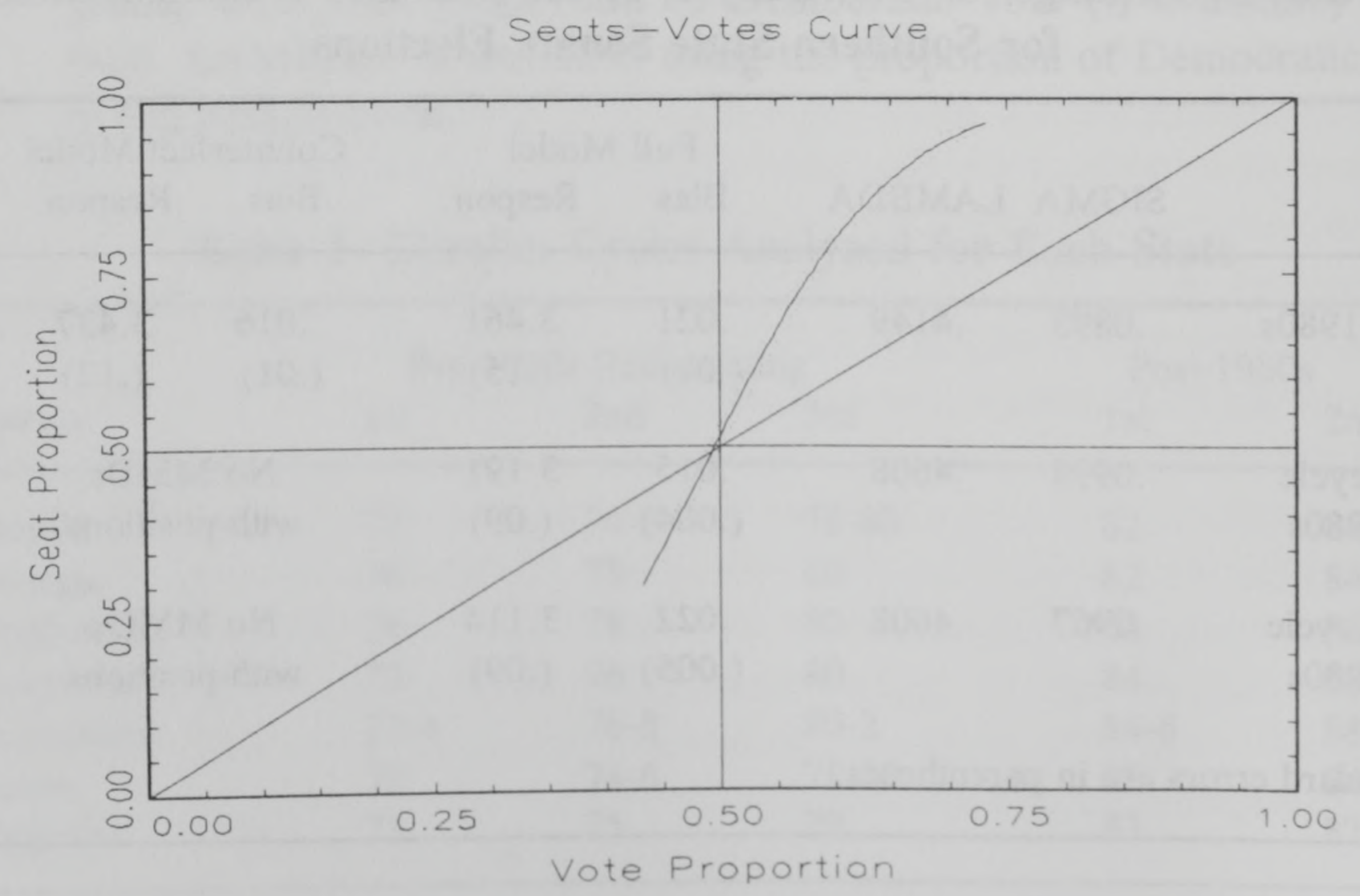


Figure 3. Seats-Votes Curve for 1980s, Second Election Cycle After Redistricting

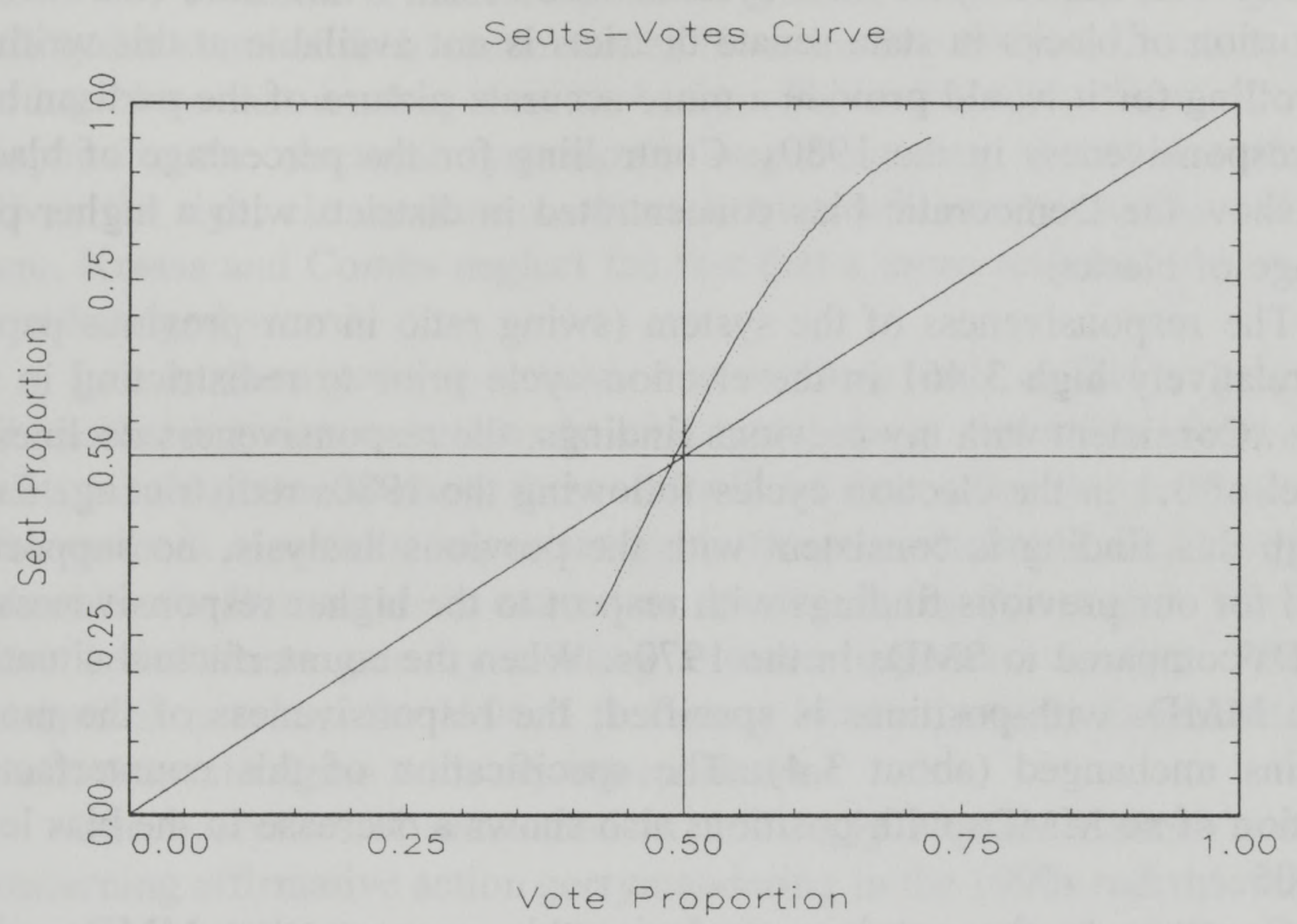

Findings

Table 2 shows that estimates for SIGMA (pooled for the pre-1980s redistricting period, and the second election cycle after the 1980s redistricting) range between .089 and .0995 for the election cycles analyzed, while estimates for LAMBDA range between .41 and .46. Because SIGMA represents a proportion, election results can be forecast to within \pm 9 to $10 \%$. Optimally, one would prefer to see lower values (about .4 to .6) for SIGMA. These high estimates most likely reflect the large proportion of imputed election results. Nonetheless, when these results are not imputed, SIGMA doubles to about .18 .

The findings show a bias toward the Democratic party ranging from $.015(1.5 \%)$ to $.022(2.2 \%)$. While the bias of the system declines by .006 in the first election cycle after redistricting in the $1980 \mathrm{~s}$, it returns to its previous level of just over .02 in the second election cycle after the $1980 \mathrm{~s}$ redistricting. This point is illustrated by examining Figures 1, 2, and 3, which show the seats-votes curve for each of these election cycles.

These findings are somewhat inconsistent with the previous analysis because they show a bias of about two percent toward the Democrats, whereas 
my previous research suggested the bias was insignificant. However, these findings are consistent with the previous analysis in the sense that they show that the seats-votes relationship is not so skewed toward the Democrats that the GOP can not compete on a system-wide basis. While time data for the proportion of blacks in state senate districts is not available at this writing, controlling for it would provide a more accurate picture of the partisan bias and responsiveness in the 1980s. Controlling for the percentage of blacks may show the Democratic bias concentrated in districts with a higher percentage of blacks.

The responsiveness of the system (swing ratio in our previous paper) is a relatively high 3.461 in the election cycle prior to redistricting in the 1980s. Consistent with my previous findings, the responsiveness declines to a level of 3.1 in the election cycles following the 1980s redistricting. Even though this finding is consistent with the previous analysis, no support is found for our previous findings with respect to the higher responsiveness of MMDs compared to SMDs in the 1970s. When the counterfactual situation of no MMDs with-positions is specified, the responsiveness of the model remains unchanged (about 3.4). The specification of this counterfactual situation of no MMDs with-positions also shows a decrease in the bias level of .005 .

Contrary to the previous analysis, this suggests that MMDs withpositions add bias at the state senate level. These findings are more consistent with the previous work that suggests that MMDs hinder GOP efforts (Jewell and Breaux; Bullock; Bullock and Gaddie 1993). These findings, however, suggest this bias is not as great as suggested by these other scholars. In this respect it is significant to note that given a standard error of .01 for the estimates of bias, these findings could be an artifact of the error in estimation. ${ }^{4}$

The validity of these findings is tested by imputing a number of other election results and replicating the above analysis without particularly robust results. While it is important to note that one should expect some variation in findings when using imputed election results, the variation is higher than expected. The differences in the estimates of bias range from less than .01 to about .03, depending on which imputed scores are used in the replication. This analysis reports the findings that were most typical. Nonetheless, this suggests a need to develop a stronger theoretical basis for developing imputed scores.

\section{Interpretation}

The decline in the responsiveness of state senate districts between redistricting periods brings us to Krassa and Combs' critique regarding our 
interpretation of the swing ratio. Krassa and Combs believe a more responsive system better protects Democratic incumbents because it converts lower vote shares into a higher proportion of Democratically controlled districts. However, to create a more responsive system, incumbents must generally relinquish some of their stable voting blocs in their districts in exchange for voting blocs that are less than favorably disposed toward them. The more responsive the electoral system, the larger number of unstable districts. Given the right circumstances, these districts will easily switch control. In sum, Krassa and Combs neglect the fact that a more responsive system is a double-edged sword.

In a more responsive system, one can lose seats as fast as gain them. Given that legislators tend to be concerned about reelection, most incumbents would prefer to know their seat will be there after the electoral storm. This point is especially important given the overwhelming majorities maintained by the Democrats in most state senates during this period. The Democrats had little to gain by creating a more responsive system. While the analysis is not done for 1994, I feel many North Carolina Democratic state senators would agree with my interpretation.

One analysis left untouched in this reply regards Bullock's critique concerning affirmative action gerrymandering in the 1990s redistricting. The data is not available to me at this time to test the generalizability of these findings for the 1990s. However, Gelman and King's (1994) methodology can be adapted to handle this question. Bullock's analysis is essentially correct. The difference between the "effects" standard guiding the 1980s redistricting process and the "intent" standard guiding the 1990s redistricting process means that the notion of compactness was discarded. Republicans appear to be the beneficiaries, but how they benefit is the major question to be answered. Bullock suggests the 1990 redistricting created a group of highly Democratically biased black-majority districts in exchange for a larger set of more responsive and/or Republican biased "bleached" districts.

\section{NOTES}

${ }^{1} \mathrm{~A}$ fuller development of this methodology can be found in Gelman and King (1994, 514-49).

${ }^{2}$ This suggests that by excluding states that had few contested districts, we may have biased the analysis toward finding a pro-Democratic electoral system.

${ }^{3}$ Appendix A in Gelman and King (1994, 549-50) describes this methodology.

${ }^{4}$ Our previous research showed that while the signs of the bias coefficients for MMDs were negative, these coefficients were statistically insignificant. 
58 | Joseph A. Aistrup

\section{REFERENCES}

Gelman, Andrew and Gary King. 1994. A Unified Method of Evaluating Electoral Systems and Redistricting Plans. American Journal of Political Science 38:514-54.

Niemi, Richard G., Simon Jackman, and Laura R. Winsky. 1991. Candidates and Competitiveness in Multimember Districts. Legislative Studies Quarterly 16:91-110. 